applicable for researchers, practitioners, policy makers, and junior trainees.

\section{THE UL SAFETY INDEX: QUANTIFYING SAFETY AROUND THE WORLD}

David Wroth, Ahreum Han. Underwriters Laboratories (UL), USA

10.1136/injuryprev-2016-042156.205

Background Assessing the state of safety amongst countries is complex, leading to poor prioritisation of resources amongst safety professionals and policy makers. The UL Safety Index is a quantification of relative safety based on societal influences and unintentional death and injury.

Methods The relationship between the indicators (societal influences and safety frameworks) and outcomes was modelled. Indicators were transformed into an index ranging from 0 (worst) to 1 (best):

$$
\text { Indicator Index Score }=\frac{x_{i}-\min x_{i}}{\max x_{i}-\min x_{i}} \text {, where } x \text { are the explanatory indicators }
$$

Drivers were computed as the arithmetic mean of the Indicators:

$$
\text { Driver Index Score }=\frac{1}{n} * \sum_{i=1}^{n} x_{i}, \text { where } x \text { are the Indicator Indices }
$$

The UL Safety Index is the geometric mean of the three Driver Indices:

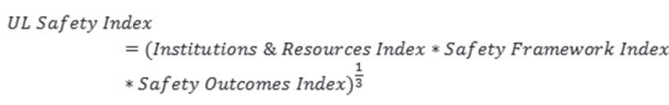

Statistical analysis of indicators and drivers against injury data confirmed correlation with outcomes.

Results Western industrialised nations are at the top of the Safety Index. Sub-Saharan Africa has much to gain from investment in safety drivers. As the Index includes factors of wealth, education and governance, human development and infrastructure issues influence the results. Consequently, solutions that address basic needs will also improve safety. South Central Asia also lags in the Index. Many of the same influences for Africa apply here as well and their Index is also affected by limited participation in international standards development.

Conclusions The relationship between societal drivers and safety outcomes confirm the need for multi-layered improvement strategies. Investment in governance, education, technology, infrastructure and economic development are correlated with fewer unintentional deaths and injuries. This implies that safety outcomes are improved through investment in key development areas. Safety science will continue to be part of a comprehensive approach as hazard mitigation and behaviour change also improve safety outcomes. The UL Safety Index improves visibility into needed investments, leading to initiatives that will save lives globally.

\section{Environmental Safety, Client Safety}

Parallel Mon 3.6

\section{COST-BENEFIT ANALYSIS OF FALL INJURIES PREVENTED BY A PROGRAMME OF HOME MODIFICATIONS}

${ }^{1}$ Michael D Keall, ${ }^{1}$ Nevil Pierse, 'Philippa Howden-Chapman, ${ }^{2}$ Jagadish Guria, ${ }^{3}$ Chris Cunningham, ${ }^{1}$ Michael G Baker. ${ }^{1}$ Otago University, Wellington, New Zealand; ${ }^{2}$ Economic Consultant, Newlands, Wellington, New Zealand; ${ }^{3}$ Massey University, Wellington, New Zealand

\subsection{6/injuryprev-2016-042156.206}

Background Injuries due to falls in the home amongst the general population impose a huge social and economic cost on society. We previously found important safety benefits of home modifications such as handrails for steps and stairs, grab rails for bathrooms, outside lighting, edging for outside steps and slip-resistant surfacing for outside surfaces such as decks.

Methods Following a single-blinded cluster randomised controlled trial (the HIPI trial), we analysed insurance payments for medically-treated home fall injuries. The benefits in terms of the value of DALYs averted and social costs of injuries were extrapolated to a national level and compared with the costs of the intervention.

Results Costs per injury per time exposed to the modified homes compared to the unmodified homes showed a reduction in the insurer costs of home fall injuries of 36\% (95\% CI: 5\%-59\%). The social benefits of injuries prevented were estimated to be at least 9 times the costs of the intervention. The benefit cost ratio can be at least doubled for older people and those with a prior history of fall injuries.

Conclusions This is the first randomised controlled trial to our knowledge to examine the benefits of home modification for reducing fall injury costs in the general population. The results show a convincing economic justification for undertaking relatively low-cost home repairs and installation of safety features.

\section{PARTNERING TO FOCUS ON CHILD INJURY PREVENTION - THE SAFEKIDS NEW ZEALAND AND HOUSING NEW ZEALAND DRIVEWAY RUN OVER CAMPAIGN}

${ }^{1}$ Alessandra Francoia, ${ }^{2}$ Ann Weaver. ${ }^{1}$ Safekids New Zealand; ${ }^{2}$ Housing New Zealand, New Zealand

10.1136/injuryprev-2016-042156.207

Background This presentation demonstrates the success of a Driveway Run over Campaign by using intersectoral collaboration to support the implementation of this child injury prevention initiative. Incorporating increased awareness, behaviour change, environmental change, and advocacy.

Housing New Zealand Corporation (HNZC) is New Zealand's largest landlord, and houses over 200,000 people. HNZC customers are lower income households, and indigenous peoples are over-represented. Most HNZ households include children. Safekids and HNZC have a shared interest in increasing the safety of vulnerable children and their families. Since 2006, Safekids and HNZC have collaborated to reduce the risk of driveway run over injuries in HNZC properties.

This presentation will describe the key components of the partnership, including the national context for this work, shared 
values frameworks, evaluation findings and key outcomes. Outcomes to date include changes in parental behaviour, changes to the physical environment of HNZC homes, and the development of design guidelines for vehicle access on high density housing sites.

Problem Children living in areas of high socio-economic deprivation are more likely to reside in high household occupancy dwellings and are more likely to be at risk. Driveway run over injuries are disproportionately experienced by Indigenous children.

Effective interventions to reduce the risk of driveway run over injuries need to target three key factors - human, vehicle and property design factors.

Driveway run-over and low-speed injuries typically involve young children, the driver is often a family member, and injuries are usually severe and/or fatal.

Results As a result of the collaboration, HNZC has commenced a multi-million dollar fencing and landscaping programme that utilises Safekids tools and messaging to reduce the risk of driveway run over injuries across 69,000 properties nationwide. In addition, a joint Safekids and HNZC nationwide public awareness campaign was developed and delivered in the spring-summer 2013. A further joint public awareness campaign was delivered in 2015-2016.

Conclusion Key take away learnings from this presentation will include:

- Increased awareness of the burden of driveway runover injuries and opportunities for effective intervention

- Key concepts that support effective intersectoral collaboration between Safekids and Housing New Zealand Corporation to reduce the risk of driveway run over injuries for vulnerable children and their families

- Outcomes and key learnings from this initiative, and future opportunities for effective child injury prevention action

\section{ON-LINE ASSESSMENT OF ENVIRONMENTAL CHARACTERISTICS OF PAEDIATRIC BICYCLING INJURIES ALBERTA, CANADA}

${ }^{1}$ Mateus Farias, ${ }^{2}$ Amy Couperthwaite, ${ }^{1}$ lan Blanchard, ${ }^{1}$ Alka Patel, ${ }^{1}$ Alberto Nettel-Aguirre, ${ }^{1}$ Brent Hagel. ' University of Calgary, Canada; ${ }^{2}$ York University, Canada

10.1136/injuryprev-2016-042156.208

Background There are few studies on the relationship between the severity of bicycle-related injury in children and characteristics of the built environment.

Methods Emergency Medical Services (EMS) 9-1-1 calls completed between 2010-2013 in Calgary and Edmonton, Alberta, Canada for bicycle injury events in children $<18$ years old were identified. These data containclinical pre-hospital variables and were linked to administrative health outcome data using a deterministic linkage strategy. Events that required hospital admission were considered severe injuries. ArcGIS software was used to identify the EMS injury locations. Virtual environmental audits were done using the Pedestrian Environmental Data Scan (PEDS) with Google Maps. The personal characteristics of the injured bicyclists and the environmental characteristics of the injury locations were examined.

Results Among all paediatric EMS calls that were linked to a health care database, 575 involved bicycle injuries. To date, we have completed 157 location audits using the PEDS instrument with Google Maps. Analysis of audits completed to date indicates
$83 \%$ of the subjects were male. Almost half (45\%) of all injuries occurred on road segments with intersections. Two-thirds of injuries occurred at locations with a lack of street crossing aids.

Conclusions We have made progress toward profiling the individual and environmental characteristics of bicycle injuries. Next steps involve completing this process for the remaining injury locations. Injuries requiring hospital admission (i.e., severe injuries) will be compared with the ones that did not (i.e., non-severe injuries) for personal (e.g., age, sex) and location (e.g., presence of intersection) variables.

\section{UNDERSTANDING THE PREVENTION OF UNINTENTIONAL INJURIES AT HOME AMONG CHILDREN UNDER FIVE YEARS FROM RAMALLAH DISTRICT: MULTIPLE-CASE STUDIES}

${ }^{1}$ Intima Alrimawi, ${ }^{2}$ Michael Craig Watson, ${ }^{3}$ Carol Hall. ${ }^{1}$ Birzeit University, Palestine; ${ }^{2}$ The University of Nottingham, UK; ${ }^{3}$ The University of Nottingham, UK

\subsection{6/injuryprev-2016-042156.209}

Background Unintentional injuries are a growing global public health problem that causes mortality, morbidity and disability among children. These injuries are most common among underfives and form a significant burden on healthcare systems, particularly in low and middle income countries. Parents, health professionals, and key peoples have a major role to play in the prevention of home injuries, as expressed in many international reports. In Palestine there is a paucity of research in this area. Moreover, most previous studies adopted quantitative approaches to investigate particular aspects of injuries. Therefore, this study aimed to explore parents', health professionals', and key people's perceptions and practices regarding the prevention of home injuries among children aged under-five years, and the potential factors that might influence such practice in Ramallah district.

Methods A case study approach was followed, whereby three parental case studies scenarios were obtained from those who live in camp, rural, and urban settings within Ramallah District. Semistructured interviews were undertaken with twelve mothers in three setting and their homes were observed (four mothers in each setting). The context that surrounds them was investigated by interviewing twenty-four health professionals who worked with children in a primary health care setting, and nine key people who worked as senior level managers within organisations concerned with children. The derived data were analysed using thematic analysis, and a template was used for the analysis of multiple case studies.

Results Parents were involved in trying to prevent child home injuries and many similarities were noticed between the perspectives of parents within the three case studies. However, many factors affected their practice and these were mainly related to lack of awareness and low financial status. Environmental factors influenced injury prevention, including: the physical environment of the house, socio-cultural environment (e.g. belief in fatalism), as well as governmental policy (e.g. lack of home safety regulations). Most of the health professionals and half of the senior managers interviewed were positive toward preventing home injuries, but workload and lack of training were the main barriers to their practice in this area.

Conclusion The evidence from this thesis shows that the causes of home injuries in Ramallah District are embedded within the families' culture, social and economic status, and are influenced by government policies and the surrounding physical 